\title{
The effectiveness of a pre-pubic four-arm NAZCA-TC mesh in treating cystocele and stress urinary incontinence simultaneously - results controlled with a pelvic floor ultrasound. A preliminary study
}

\author{
Edyta Wlaźlak ${ }^{1}$, Tomasz Kluz ${ }^{2}$, Andrzej Wróbel' ${ }^{3}$, Magda Krzycka' ${ }^{1}$, Grzegorz Surkont ${ }^{1}$ \\ ${ }^{1}$ Clinic of Operative Gynecology and Gynecologic Oncology, $1^{\text {st }}$ Department of Gynecology and Obstetrics, \\ Medical University of Lodz, Poland \\ 2Department of Obstetrics and Gynecology, Fryderyk Chopin University Hospital No. 1, Faculty of Medicine, \\ Rzeszow University, Rzeszow, Poland \\ ${ }^{3}$ Second Department of Gynecology, Medical University of Lublin, Poland
}

\begin{abstract}
Objectives: It is controversial whether pelvic organ prolapse and stress urinary incontinence (SUI) should be treated simultaneously with a single surgery or separately with two procedures. The pre-pubic four-arm NAZCA-TC ${ }^{\circledR}$ mesh was invented to treat cystocele and SUI with a single procedure. The objective of this study is to analyze short-term results after the implantation of NAZCA-TC mesh.

Material and methods: A total of 18 women underwent the evaluation of results of mesh implantation within a 24 to 36 months follow-up. Pre-operatively, patients were examined under standardized conditions. Postoperatively we analyzed the following: standardized interview and examination as well as pelvic floor ultrasound: $2 \mathrm{D}$ with a transvaginal probe and 4D with an abdominal probe.

Results: There was one case of intraoperative bladder damage noticed and repaired followed with NAZCA implantation. In 2 cases vaginal erosion was found that healed successfully after re-operation. In 3 cases hematomas were observed but resolved spontaneously. After the surgery there was a statistically significant improvement of prolapse in anterior $(p<0.0003)$ and in central $(p<0.001)$ compartment. Six women $(33.3 \%)$ had no stress urinary incontinence symptoms during the control visit but we did not find a statistically significant improvement in SUI symptoms after the procedure. We recorded no case of hypomobile urethra after the surgery. The mesh covered $>50 \%$ of the urethral length in all of the patients.

Conclusions: Mid-term results showed that implantation of NAZCA TC mesh allows to achieve statistically significant improvement in reducing cystocele coexisting with enterocele in over $65 \%$ of patients. A complete cure from stress urinary incontinence was confirmed in $1 / 3$ of patients. NAZCA-TC covered more than $50 \%$ of the urethral length, which can possibly have a negative influence on the effectiveness of the suburethral tape.
\end{abstract}

Key words: cystocele, stress urinary incontinence, prepubic four-arm transvaginal mesh, pelvic floor ultrasound, PFS-TV, transvaginal probe

Ginekologia Polska 2017; 88, 11: 579-584

\section{INTRODUCTION}

Stress urinary incontinence (SUI) is the most common type of urinary incontinence in women [1-4]. SUI and pelvic organ prolapse (POP) are often the reasons for operative treatment, especially in ageing populations [5-11]. There are no recommendations regarding an optimal surgical intervention in different clinical situations. Thus, controversies may arise in a situation where POP coexists with overt or occult SUI. In such case the question is whether POP and coexisting SUI should be addressed together at one proce- 
dure or not. While occult incontinence may coexist in up to $30 \%$ of women with POP, about $40-50 \%$ of women with POP observe a significant SUI $[12,13]$. NAZCA-TC is a mesh with four arms: two pre-pubic and two transobturator. It was invented to treat anterior vaginal wall prolapse alone or together with SUI [12].

The polypropylene mesh and its arms are well visible during pelvic floor ultrasound. That is why many specialists advocate the use of sonography to control the effects after urogynecological procedures where such slings are used [14]. Introital pelvic floor sonography with a transvaginal probe (PFS-TV) was previously used to evaluate patients with SUI before and after anti-incontinence suburethral sling implantation $[15,16]$. It was also found useful to evaluate POP and mesh used for treating it with a 2D or 4D pelvic floor ultrasound performed perineally with a transabdominal probe (PFU-TA) [14].

Urethral hypomobility was found to be one of the risk factors for failure of the implanted anti-incontinence suburethral tape. PFS-TV in turn was found to be very useful in detecting hypomobility of the urethra $[15,16]$.

In patients who had two tapes implanted, a collision phenomenon between 2 anti-incontinence suburethral tapes was observed during PFS-TV examination $[17,18]$. That is why the literature suggests that the tape located near the middle part of the urethra be first excised and a new tape be implanted a few weeks later [17-19]. Because NAZCA-TC is implanted near the urethra, it would be valuable to check its location along the urethra and to evaluate its influence on the urethral mobility.

In the literature there is only one study that analyzes the influence of NAZCA-TC implantation on SUI [12]. There are no studies concerning NAZCA-TC evaluation using PFS-TV or PFU-TA.

\section{OBJECTIVES}

The objective of this study is to evaluate the results of NAZCA-TC mesh implantation in women with POP and coexisting SUI symptoms using PFS-TV and PFU-TA.

\section{MATERIAL AND METHODS}

NAZCA-TC ${ }^{\circledR}$ mesh (by Promedon, Argentina) was implanted in 21 patients. The mesh is made of type I polypropylene monofilament with a density of $60.5\left[\mathrm{~g} / \mathrm{m}^{2}\right]$. The mesh pore size is $0.5-1[\mathrm{~mm}]$, the mesh thickness is $0.47[\mathrm{~mm}]$ and the filament diameter is 0.14 [mm]. The central part of the sling has 16 circular orifices with $6[\mathrm{~mm}]$ in diameter each, which enhances tissue integration and decreases the amount of synthetic material implanted allowing thus a greater flexibility. The sling has 2 arms - two pre-pubic and two transobturator. One pre-pubic and two transobturator needles with removable and ergonomic handles complete the set [12]. All operated women had symptoms of SUI and a cystocele of stage 2 or higher as per Pelvic Organ Prolapse Quantification (POP-Q) system [9, 10, 20].

One and the same experienced surgeon (T.K.) performed the surgery on all the patients in the study. The data has been obtained retrospectively from a total of 18 patients who attended the control visit between 24 and 36 months following the procedure.

Pre-operatively, patients were examined under standardized conditions. Pelvic organ prolapse (POP) was classified in accordance with POP-Q system [20]. SUI was confirmed by a cough test [21].

The surgery and mesh implantations were performed according to the technique described by Palma et al. [12]

When it comes to the postoperative analysis, we included the following: standardized interview and examination that includes analysis of POP using POP-Q scale; urinary continence evaluated with a cough test and a PFS-TV — a standardized pelvic floor ultrasound using GE Voluson Expert: 2D introitally with a transvaginal probe (PFS-TV) and 4D translabially with an abdominal probe (PFU-TA).

The volume of urine in the bladder was evaluated during transabdominal ultrasound by performing three-plane measurements of the bladder calculated by the ultrasound system. We have evaluated urinary incontinence in patients with 250-350 [ml] of urine in the bladder. PFS-TV was performed under standardized conditions [15, 22, 23]. Cough test was performed in patients in lithotomy position. If the test was negative, it was repeated in standing.

During the post-operative visit urethral length, mobility and funneling with urine flow was evaluated with PFS-TV on a sagittal view as previously described [15, 22-26]. The urethral mobility was evaluated as a vector calculated from measurements obtained during PFS-TV according to the method described by Viereck. This parameter is also called a linear dorsocaudal movement $(\operatorname{LDM})[15,24]$. The urethra was defined as hypomobile when the value of the vector was $\leq 5[\mathrm{~mm}]$, normomobile when more than $5[\mathrm{~mm}]$ but less than $15[\mathrm{~mm}]$ and hypermobile when $\geq 15[\mathrm{~mm}][15,23]$. The urethral funneling with a urine flow, which was observed during Valsalva maneuver in PFS-TV, was regarded as a confirmation of SUI that was previously recorded with a positive cough test $[25,26]$. We diagnosed no SUI when there were no clinical symptoms or when SUI was observed by the patient only periodically while sitting and standing cough test and PFS-TV examination were all negative. A first degree of SUI was diagnosed when the patient reported SUI symptoms to be periodical (from time to time, not every day) and the cough test as well as SUI during PFS-TV exam were positive. A 2+ degree of SUI was diagnosed when patients reported to have symptoms every day and the cough test was positive, which had to be confirmed during PFS-TV. 
The location of urethral end of NAZCA-TC mesh was measured during PFS-TV on a sagittal view similarly to the measurements proposed by Kociszewski et al. for the suburethral tape $[15,23]$. We measured the shortest distance between the mesh and the hypoechoic urethra. It was called mesh-urethra distance measured in [mm] (Figure 1). We calculated the mesh position relative to the urethral length in \% according to the formula (1):

Relative mesh position $=$ distance of the distal end of the mesh from the bladder neck*100\%/sonographic urethral length (Figure 1).

PFU-4D was performed under standardized conditions. Hiatal dimensions at rest and during maximal Valsalva lasting minimum 5 seconds were measured in the plane of minimal hiatal dimensions, as described previously. Levator trauma was identified by tomographic ultrasound (TUI) as described previously [14, 27-28].

The statistical analysis was performed with STATISTICA 7.0 software of Stat Soft. The calculations of median, arith-
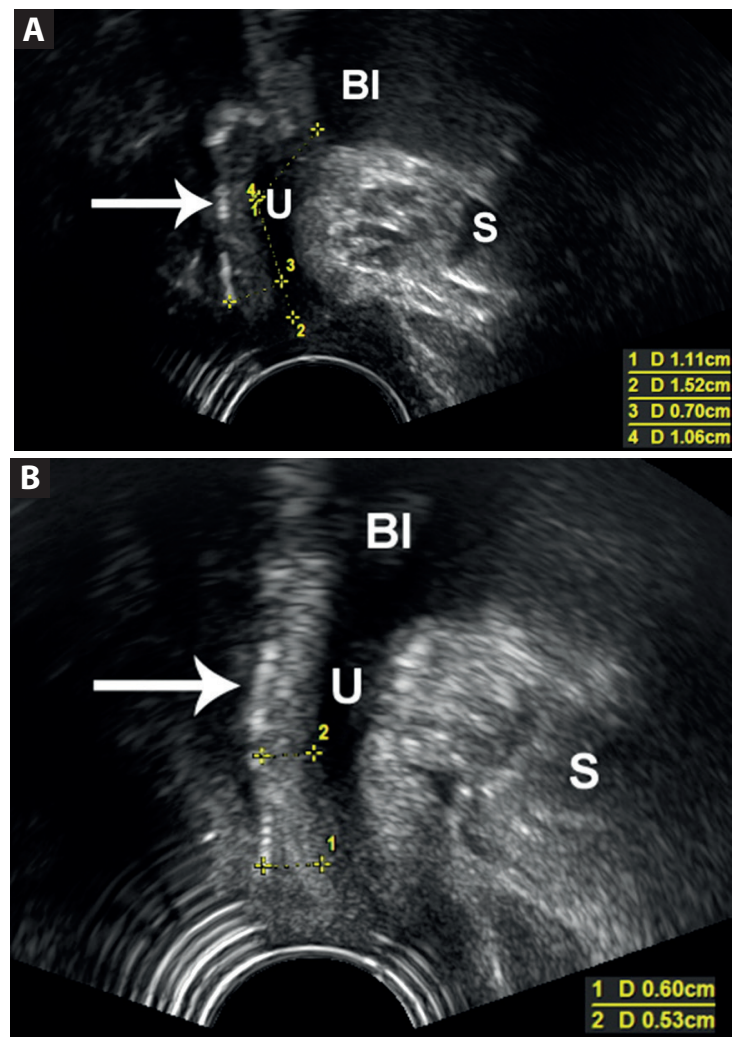

Figure 1. PFS-TV: evaluating mesh location. A. Evaluating relative mesh position. Legend: $1+2$ - urethral length; 3 - projection of distal end of the mesh on urethral axis; $4+1$ - distance between distal end of the mesh and bladder neck (internal urethral orifice); $\mathrm{BI}$ - bladder; $\mathrm{U}$ - urethra; $\mathrm{S}$ - symphysis pubis; relative mesh position $=1+2 / 4+1 \times 100 \%$; B. Evaluating mesh-urethra distance. Legend: 1 and 2 - distances between mesh and hypoechoic urethra, mesh urethra distance is the smallest distance between tape and hypoechoic urethra: in this case measurement No. 2; BI — bladder; $\mathrm{U}$ - urethra; $\mathrm{S}$ - symphysis pubis metic mean and standard deviation were done. Student's t-test was applied for testing the significance of differences for the dependent variables.

\section{RESULTS}

All 18 patients had the implantation of NAZCA mesh in a single procedure and it was their only treatment procedure. The mean age of women was 62 years (range, 40-78). The mean BMI was 29.2 [kg/ $\left.\mathrm{cm}^{2}\right]$ (range, 22.2-38.0). There were no statistically significant differences between SUI cured and not-cured in age and BMI. Three women were premenopausal, the rest were 3 to 24 years after menopause (Table 1). One patient was taking insulin because of diabetes and 9 patients had hypertension. Four women were smoking > 10 cigarettes daily. One patient had a vacuum-assisted delivery, 3 patients had spontaneous deliveries and 1 patient had 3 spontaneous deliveries and a caesarean section. The rest delivered only vaginally from 1 to $7 \mathrm{ti}$ mes (mean $=3$ ). Patients' first baby was delivered between the age of 19 and 35 (mean =23.3). One woman had an abdominal hysterectomy in the history (leiomyomas) and one had a hysterectomy with bilateral salpingo-oophorectomy because of a benign ovarian tumor. None of the patients had a previous urogynecological surgery.

All of the patients had a cystocele of at least $2^{\text {nd }}$ degree (POP-Q scale) confirmed during the preoperative examination. Additionally, an enterocele of $2^{\text {nd }}$ degree was found in 5 patients and of $1^{\text {st }}$ degree in 9 patients. In 7 cases examination revealed a rectocele of (patients with enterocele 1+). After the NAZCA implantation the prolapse improved significantly in both the anterior $(p<0.0003)$ and central $(p<0.001)$ compartment. In the posterior compartment the differences were not statistically significant. At the control visit a POP of $2^{\text {nd }}$ degree was noticed in 6 patients in the anterior compartment, in 1 patient in the central compartment and in 1 patient in the posterior compartment (Table 2). Only 2 patients (11.1\%) did not notice any significant improvement of POP symptoms.

Before the surgery all of the patients suffered from SUI $2^{\text {nd }}$ degree that was confirmed during cough test. There was no statistically significant improvement in SUI symptoms after the NAZCA implantation. Although 8 patients (44.4\%) observed symptoms to disappear or subside, 5 (27.8\%) reported no change and other 5 (27.8\%) reported the symp-

\section{Table 1. Demographic data of the studied group}

\begin{tabular}{|l|c|}
\hline Mean age of women (min-max) & 62.0 years $(40-78)$ \\
\hline Mean BMI (min-max) & $29.2\left[\mathrm{~kg} / \mathrm{cm}^{2}\right](22.2-38.0)$ \\
\hline Number of premenopausal women & 3 \\
\hline Number of postmenopausal women & 15 \\
\hline
\end{tabular}


Table 2. POP-Q evaluation before and after the NAZCA implantation

\begin{tabular}{|l|c|c|c|}
\hline & Preoperative examination & Postoperative examination & p value \\
\hline Cystocele of at least $2^{\text {nd }}$ degree & 15 & 6 & $p<0.0003$ \\
\hline Enterocele of at least $2^{\text {nd }}$ degree & 5 & 1 & $p<0.001$ \\
\hline Rectocele of at least $2^{\text {nd }}$ degree & 0 & 1 & Not statistically significant \\
\hline
\end{tabular}

toms to worsen. Only 6 patients (33.3\%) had no stress urinary incontinence symptoms at the control visit, of which 2 reported a periodical SUI despite a negative cough test and no signs of SUI during PFS-TV. The rest suffered from SUI $2^{\text {nd }}$ degree.

Preoperatively, symptoms of dry overactive bladder were reported by $61.1 \%$ of patients. After the surgery $72.2 \%$ of them noticed a significant improvement. There was no case of urge de novo or wet overactive bladder.

Pelvic floor ultrasound revealed the mesh to be rolled up in 11 cases (61.1\%) (Figure 2).

Mean urethral length in SUI cured and not-cured patients was nearly the same: $2.97 \mathrm{~cm}$ vs. $2.99 \mathrm{~cm}$ (NS). PFS-TV showed that the mesh was covering more than $50 \%$ of the
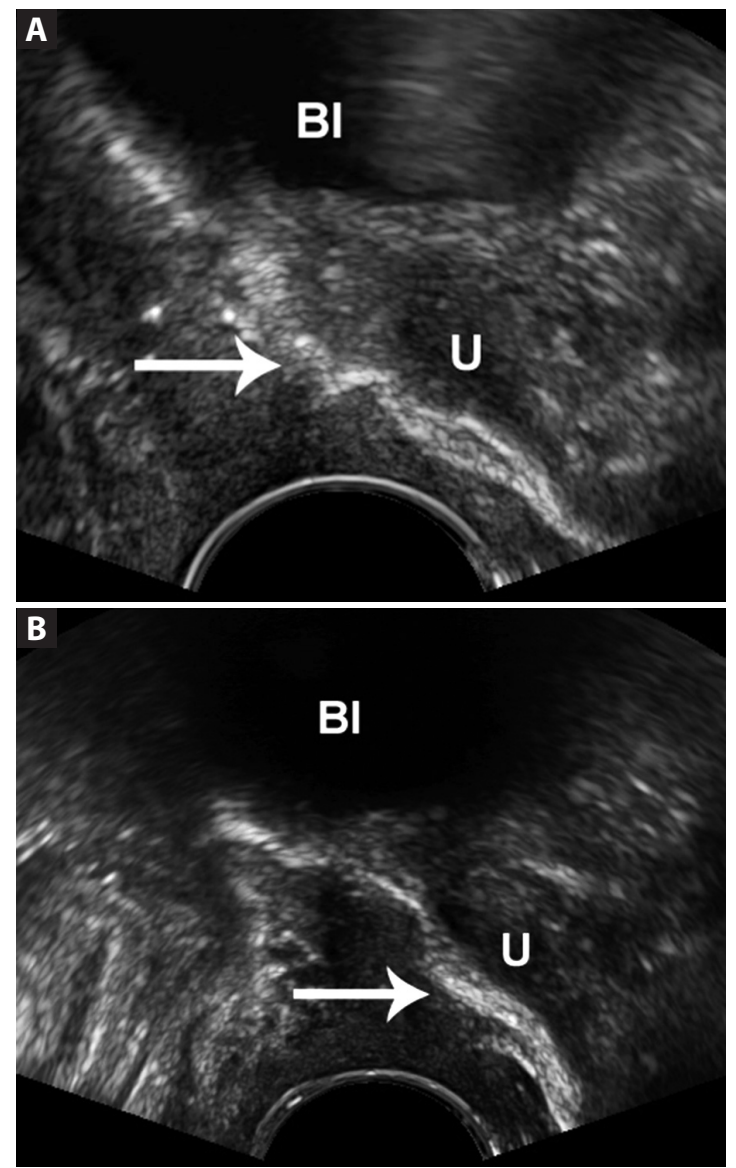

Figure 2. PFS-TV: NAZCA mesh, covering nearly the whole length of the urethra. A. Rolled-up; B. Without signs of rolling urethral length in all of the patients and $75 \%$ of the length in $72.2 \%$ of patients (Figure 2). The mean relative mesh position was $80.3 \%$ (range, 55.6-94.1\%): in SUl cured group: $79,8 \%$, in SUI not-cured group: $80,1 \%$ (NS). The mean mesh-urethra distance was 4.40 [mm] (range, 0.18-7.50), in SUI cured group: 4,4 mm, in SUI not-cured group: 4,5 mm (NS).

After the NAZCA implantation there was no patient with a hypomobile urethra. PFS-TV showed a hypermobile urethra in 12 patients (66.7\%) and a normomobile urethra in 6 patients (33.3\%). The mean LDM value was 19.3 [mm] (range, 6.1-31.4). The differences in mean LDM between SUI cured group and SUI not-cured group were not statistically significant.

PFU-4D revealed that the mean hiatal area was $23.5 \mathrm{~cm}^{2}$ (15.6-39.0) at rest and $28.4 \mathrm{~cm}^{2}(18.1-47.1)$ at maximal Valsalva. In 3 patients (16.7\%) a unilateral puborectalis avulsion was identified. $72.2 \%$ of patients were at increased risk of postoperative POP recurrence due to hiatal area $>25\left[\mathrm{~cm}^{2}\right]$ and/or levator avulsion. In SUI cured group mean hiatal area at rest was $24.0 \mathrm{~cm}^{2}$ and during maximal Valsalva $-29.2 \mathrm{~cm}^{2}$, in SUI not cured group respectively $22.3 \mathrm{~cm}^{2}$ and $26.7 \mathrm{~cm}^{2}$ (NS).

Bladder damage has occurred in one patient that was found intraoperatively. It was repaired followed with NAZCA implantation. Vaginal erosion was noticed in 2 cases (11.1\%) and after re-operation it was successfully healed. The erosions were identified among smokers only. In 5 women (27.8\%) we noted a post-void residual $>100 \mathrm{~mL}$, which lasted $<7$ days. In 3 women (16.7\%) hematomas were detected but resolved spontaneously. In 5 cases (27.8\%) infection of urinary tract has occurred soon after the surgery.

A total of 3 patients did not attend the control visit but NAZCA implantation and hospitalization was complications free.

\section{DISCUSSION}

The pathophysiology of SUI is not fully understood. Recently, it has been claimed that urethral hypermobility and sphincter weakness called intrinsic sphincter deficiency can explain SUI in most of the cases [14, 29-31].

Suburethral tapes are highly successful in treating SUI but the mechanism of their action as well the reasons for eventual failure remain quite unknown. Urethral hypomobility is a generally accepted risk factor for failure. There are studies using PFS-TV showing that the relative tape position, the tape-urethra distance and the urethral mobility toge- 
ther have a definitive impact on the cure rate [15, 22, 23]. However, Dietz et al., using PFU-TA, was not able to confirm the results obtained during PFS-TV [32].

$\mathrm{POP}$ is a common female disease [33]. It often co-exists with overt SUI or occult SUI. It is still not clear if combining the treatment of POP and SUI to one procedure is an optimal choice. Yet, compared to anterior mesh procedure where 39$-77 \%$ of women became free of SUI symptoms, combining anterior mesh with a suburethral tape implantation gave a 78-95\% cure rate. However, the incidence of complications was significantly higher after a combined procedure [13, 34].

The study of Palma et al. evaluates a total of 104 women who had NAZCA TC implantation, of which 31 had POP coexisting with SUI pre-operatively. Only two of them (6.5\%) report treatment failure after 12 months follow-up [12]. In the study of Delroy et al. 79 women underwent either a classic anterior repair or a method using NAZCA TC but urinary incontinence was not analyzed in that study [35]. In our population in turn, the objective cure rate from SUI was $33 \%$. Subjective cure or satisfactory improvement was expressed by $44 \%$ of the patients. Yet, it is not clear why the difference between our results and those of Palma's is so big. It might be that the reason lies in the differences in the operating technique or in the very population of patients.

Two available studies concerning NAZCA TC report $5.0-5.7 \%$ cases of erosions, $4.0-4.5 \%$ cases of increased bleeding and $5-6 \%$ of patients with post-void residual lasting $<7$ days. A urethral perforation happened in up to $2.5 \%$ of procedures, while bladder perforation in $0 \%$ of cases. Urinary tract infections (UTI's) were noticed by $20 \%$ of patients. A statistically significant improvement was observed in all compartments but additional procedure for posterior or central compartment in more than $50 \%$ of women had to be performed [12,35].

Compared to the two studies mentioned above, the risk of complications in our population was similar. We did not record a statistically significant improvement in the posterior compartment since our patients had the anterior mesh implantation as the only procedure. It is worth highlighting that although $72.2 \%$ of patients were at a higher risk of postoperative POP recurrence (hiatal area $>25 \mathrm{~cm}^{2}$ and/or levator avulsion), 24-36 months following the procedure we confirmed a statistically significant improvement of prolapse in both the anterior and central compartment.

We did not find a negative influence of the sling on the urethral mobility, as there was no case of hypomobility after NAZCA TC implantation. In some cases the mesh-urethra distance was less than $3[\mathrm{~mm}]$ but we did not notice urge de novo in these patients. Kociszewski et al. observed a higher risk of urge de novo in cases of suburethral tape implantation when the tape-urethra distance was $<3[\mathrm{~mm}][22,23]$.
The mesh was covering more than $50 \%$ of the urethral length in $100 \%$ of our patients and $75 \%$ of the length in $72.2 \%$ of patients. This may theoretically be the reason for the collision between mesh and suburethral tape, which may complicate the SUI cure after the tape implantation [17, 18]. Therefore, it would be interesting to analyze the effects of suburethral tape implantation in women with persistent SUI after NAZCA TC implantation.

There exist some limitations of our study. The analysis was retrospective and the ultrasound scan was performed after the surgery only. Also, we did not use standardized questionnaires for the evaluation. On the other hand, one and the same experienced surgeon performed all of the NAZCA implantations and the results were objectively evaluated using a clinical, PFS-TV and PFU-TA examination. The results of our study suggest the need to perform some prospective randomized studies confronting comparatively the transobturator mesh with and without a simultaneous suburethral sling implantation.

\section{CONCLUSIONS}

Mid-term results showed that implantation of NAZCA TC mesh allows to achieve statistically significant improvement in reducing cystocele coexisting with enterocele in over $65 \%$ of patients. A complete cure from stress urinary incontinence was confirmed in 1/3 of patients. NAZCA TC covered more than $50 \%$ of the urethral length, which can possibly have a negative influence on the effectiveness of the suburethral tape.

\section{REFERENCES}

1. Sandvik H, Hunskaar S, Vanvik A, et al. Diagnostic classification of female urinary incontinence: an epidemiological survey corrected for validity. J Clin Epidemiol. 1995; 48(3): 339-343, indexed in Pubmed: 7897455.

2. Stangel-Wojcikiewicz K, Piwowar M, Jach R, et al. Quality of life assessment in female patients 2 and 4 years after muscle-derived cell transplants for stress urinary incontinence treatment. Ginekol Pol. 2016; 87(3): 183-189, indexed in Pubmed: 27306126.

3. Surkont G, Wlaźlak E, Suzin J. Urinary incontinence in women - social, medical and scientific problem. Menopause Rev. 2003; 1: 59-65.

4. Surkont G, Wlaźlak E, Dunicz-Sokolowska A, et al. [The efficacy of SU treatment with Burch colposuspension evaluated with use of ITT analysis]. Ginekol Pol. 2007; 78(5): 378-380, indexed in Pubmed: 17867329.

5. Guyomard A, Delorme E. Transvaginal treatment of anterior or central urogenital prolapse using six tension-free straps and light mesh. Int J Gynaecol Obstet. 2016; 133(3): 365-369, doi: 10.1016/j.ijgo.2015.10.016, indexed in Pubmed: 26971260.

6. Surkont G, Wlazlak E, Kazimierak W, et al. [The influence of SUI operative treatment with use of IVS tape on quality of life]. Ginekol Pol. 2007; 78(5): 381-383, indexed in Pubmed: 17867330.

7. Surkont G, Wlaźlak E, Petri E, et al. Standardized modified colposuspension - mid-term results of prospective studies in one centre. Ann Agric Environ Med. 2015; 22(2): 293-296, doi: 10.5604/12321966.1152082, indexed in Pubmed: 26094526.

8. Surkont G, Wlaźlak E, Suzin J. Long-term risk of complications after mid-urethral sling IVS implantation. Ann Agric Environ Med. 2015; 22(1): 163-166, doi: 10.5604/12321966.1141388, indexed in Pubmed: 25780848.

9. Lemos N, Korte JE, Iskander M, et al. Center-by-center results of a multicenter prospective trial to determine the inter-observer correlation of 
the simplified POP-Q in describing pelvic organ prolapse. Int Urogynecol J. 2012; 23(5): 579-584, doi: 10.1007/s00192-011-1593-y, indexed in Pubmed: 22083515.

10. Parekh M, Swift S, Lemos N, et al. Multicenter inter-examiner agreement trial for the validation of simplified POPQ system. Int Urogynecol J. 2011; 22(6): 645-650, doi: 10.1007/s00192-011-1395-2, indexed in Pubmed: 21431391.

11. KluzT, WlaźlakE, Surkont G. Transvaginal six-arm mesh OPUR in women with apical pelvic organ prolapse - analysis of short-term results, peIvic floor ultrasound evaluation. Ginekol Pol. 2017; 88(6): 302-306, doi: 10.5603/GP.a2017.0057, indexed in Pubmed: 28727128

12. Palma P, Riccetto $C$, Prudente A, et al. Monoprosthesis for anterior vaginal prolapse and stress urinary incontinence: midterm results of an international multicentre prospective study. Int Urogynecol J. 2011; 22(12): 1535-1541, doi: 10.1007/s00192-011-1481-5, indexed in Pubmed: 21720913.

13. van der Ploeg JM, Oude Rengerink K, van der Steen A, et al. Dutch Urogynaecology Consortium. Transvaginal prolapse repair with or without the addition of a midurethral sling in women with genital prolapse and stress urinary incontinence: a randomised trial. BJOG. 2015; 122(7): 1022-1030, doi: 10.1111/1471-0528.13325, indexed in Pubmed: 25754458.

14. Wlaźlak E, Surkont G, Shek KaL, et al. Can we predict urinary stress incontinence by using demographic, clinical, imaging and urodynamic data? Eur J Obstet Gynecol Reprod Biol. 2015; 193: 114-117, doi: 10.1016/j. ejogrb.2015.07.012, indexed in Pubmed: 26291686.

15. Wlaźlak E, Viereck V, Kociszewski J, et al. Role of intrinsic sphincter deficiency with and without urethral hypomobility on the outcome of tape insertion. Neurourol Urodyn. 2017; 36(7): 1910-1916, doi: 10.1002/nau.23211, indexed in Pubmed: 28139863.

16. Viereck V, Kuszka A, Rautenberg O, et al. Do different vaginal tapes need different suburethral incisions? The one-half rule. Neurourol Urodyn. 2015; 34(8): 741-746, doi: 10.1002/nau.22658, indexed in Pubmed: 25176293.

17. Viereck V, Rautenberg $\mathrm{O}$, Kociszewski J, et al. Midurethral sling incision: indications and outcomes. Int Urogynecol J. 2013; 24(4): 645-653, doi: 10.1007/s00192-012-1895-8, indexed in Pubmed: 22875405.

18. Kociszewski J, Kolben S, Barski D, et al. Complications following Tension-Free Vaginal Tapes: Accurate Diagnosis and Complications Management. Biomed Res Int. 2015; 2015: 538391, doi: 10.1155/2015/538391, indexed in Pubmed: 25973423

19. Kociszewski J, Majkusiak W, Pomian A, et al. The Outcome of Repeated Mid Urethral Sling in SUI Treatment after Vaginal Excisions of Primary Failed Sling: Preliminary Study. Biomed Res Int. 2016; 2016: 1242061, doi: 10.1155/2016/1242061, indexed in Pubmed: 27999787.

20. Bump RC, Mattiasson A, BøK, et al. The standardization of terminology of female pelvic organ prolapse and pelvic floor dysfunction. Am J Obstet Gynecol. 1996; 175(1): 10-17, indexed in Pubmed: 8694033.

21. Staskin D, Kelleher C, Avery K, et al. et al. Initial Assessment of Urinary and Fecal Incontinence in Adult Male and Female Patients In: Abrams P. (eds.). Incontinence. Health Publication Ltd. ; 2009: 331-412.

22. Kociszewski J, Rautenberg O, Kuszka A, et al. Can we place tension-free vaginal tape where it should be? The one-third rule. Ultrasound Obstet
Gynecol. 2012; 39(2): 210-214, doi: 10.1002/uog.10050, indexed in Pubmed: 21793084

23. Kociszewski J, Rautenberg O, Kolben S, et al. Tape functionality: position change in shape, and outcome after TVT procedure-mid-term results. Int Urogynecol J. 2010; 21(7): 795-800, doi: 10.1007/s00192-010-1119-Z, indexed in Pubmed: 20204326.

24. Viereck V, Pauer HU, Hesse O, et al. Urethral hypermobility after anti-incontinence surgery - a prognostic indicator? Int Urogynecol J Pelvic Floor Dysfunct. 2006; 17(6): 586-592, doi: 10.1007/s00192-006-0071-4, indexed in Pubmed: 16538422.

25. Bergström BoS. Curative mechanisms of two tension-free vaginal tape positions. Theoretical comments based on the urethral hanging theory of female stress urinary incontinence. Neurourol Urodyn. 2017; 36(8): 2181-2183, doi: 10.1002/nau.23229, indexed in Pubmed: 28185298.

26. Wlazlak E, Viereck V, Surkont $G$, et al. The significance of urethral funneling and urine flow (pf-ultrasound) in evaluating stress urinary incontinence [Abstract]. Poster ICS 2014; Rio de Janeiro 20th-24th October 2014. Available from: www ics org/Abstracts/Publish/218.; 000234: pdf.

27. Dietz HP, Shek C, Clarke B. Biometry of the pubovisceral muscle and levator hiatus by three-dimensional pelvic floor ultrasound. Ultrasound Obstet Gynecol. 2005; 25(6): 580-585, doi: 10.1002/uog.1899, indexed in Pubmed: 15883982.

28. Dietz HP, Bernardo MJ, Kirby A, et al. Minimal criteria for the diagnosis of avulsion of the puborectalis muscle by tomographic ultrasound. Int Urogynecol J. 2011; 22(6): 699-704, doi: 10.1007/s00192-010-1329-4, indexed in Pubmed: 21107811.

29. DeLancey J.Why do women have stress urinary incontinence? Neurourology and Urodynamics. 2010; 29(S1): S13-S17, doi: 10.1002/nau.20888.

30. Blaivas JG, Olsson CA. Stress incontinence: classification and surgical approach. J Urol. 1988; 139(4): 727-731, indexed in Pubmed: 3352031.

31. DeLancey JOL, Trowbridge ER, Miller JM, et al. Stress urinary incontinence: relative importance of urethral support and urethral closure pressure. J Urol. 2008; 179(6): 2286-90; discussion 2290, doi: 10.1016/j. juro.2008.01.098, indexed in Pubmed: 18423707.

32. Chantarasorn V, Shek KaL, Dietz HP. Sonographic appearance of transobturator slings: implications for function and dysfunction. Int Urogynecol J. 2011; 22(4): 493-498, doi: 10.1007/s00192-010-1306-y, indexed in Pubmed: 20967418.

33. Lenz F, Doll S, Sohn C, et al. Anatomical Position of Four Different Transobturator Mesh Implants for Female Anterior Prolapse Repair. Geburtshilfe Frauenheilkd. 2013; 73(10): 1035-1041, doi: 10.1055/s-0033-1350700, indexed in Pubmed: 24771893.

34. Borstad $E$, Abdelnoor M, Staff AC, et al. Surgical strategies for women with pelvic organ prolapse and urinary stress incontinence. Int Urogynecol J. 2010; 21(2): 179-186, doi: 10.1007/s00192-009-1007-6, indexed in Pubmed: 19940978.

35. Delroy CA, Castro Rd, Dias MM, et al. The use of transvaginal synthetic mesh for anterior vaginal wall prolapse repair: a randomized controlled trial. Int Urogynecol J. 2013; 24(11): 1899-1907, doi: 10.1007/s00192013-2092-0, indexed in Pubmed: 23632800. 